\title{
Proteomic Profile of Sorafenib Resistance in Hepatocellular Carcinoma; GRP78 Expression Is Associated With Inferior Response to Sorafenib
}

\author{
YIN-HSUN FENG ${ }^{1,2}$, CHAO-LING TUNG $^{1}$, YU-CHU SU ${ }^{3,4}$, CHAO-JUNG TSAO $^{5}$ and TING-FENG WU ${ }^{6}$ \\ ${ }^{1}$ Division of Hematology and Oncology, Department of Internal Medicine, \\ Chi-Mei Medical Center, Tainan, Taiwan, R.O.C.; \\ ${ }^{2}$ Department of Nursing, Chung Hwa University of Medical Technology, Tainan, Taiwan, R.O.C.; \\ ${ }^{3}$ Department of Biochemistry and Molecular Biology, College of Medicine, \\ National Cheng Kung University, Tainan, Taiwan, R.O.C.; \\ ${ }^{4}$ Department of Otolaryngology, National Cheng Kung University Hospital, College of Medicine, \\ National Cheng Kung University, Tainan, Taiwan, R.O.C.; \\ ${ }^{5}$ Department of Hematology and Oncology, Chi-Mei Medical Center, Liouying Campus, Tainan, Taiwan, R.O.C.; \\ ${ }^{6}$ Department of Biotechnology, Southern Taiwan University of Science and Technology, Tainan, Taiwan, R.O.C.
}

\begin{abstract}
Background/Aim: The outcome of patients with advanced hepatocellular carcinoma (HCC) remains poor and therapeutic options, including sorafenib, the first anticancer drug proved to prolong survival in patients with advanced HCC, are limited. However, no clinically useful predictive biomarker for sorafenib has been reported. Materials and Methods: We exploited two-dimensional gel electrophoresis coupled with mass spectrometry to find deregulated proteins by using conditioning of a sorafenibresistant HCC cell line, Huh7. Tumor samples from 60 patients with HCC treated with sorafenib were analyzed and correlated with survival outcome. Results: Comparative proteomics indicated three proteins including, $78 \mathrm{kDa}$ glucose related protein (GRP78), 14-3-3E, and heat shock protein $90 \beta$ (HSP90 $\beta)$. The three proteins were overexpressed in sorafenib-resistant Huh7 cells. In HCC tumor samples from patients treated with sorafenib, $73 \%$ of tumor samples had a high expression of GRP78, 18\% had high 14-
\end{abstract}

This article is freely accessible online.

Correspondence to: Yin-Hsun Feng, Division of Hematology and Oncology, Department of Internal Medicine, Chi-Mei Medical Center, 901 Chung-Hwa Road, Tainan, 71004, Taiwan, R.O.C. Tel: +886 62812811 ext. 57117, Fax: +886 62828928, e-mail: yinhsun. feng@gmail.com; Ting-Feng Wu, Department of Biotechnology, Southern Taiwan University of Science and Technology, 1 Nan-Tai Street, Tainan, 71004, Taiwan, R.O.C. Tel: +886 62533131 ext. 3935, Fax: +886 62425747, e-mail: wutingfe@stust.edu.tw

Key Words: Hepatocellular carcinoma, sorafenib, resistance, GRP78. 3-3e expression and $85 \%$ had high HSP9O $\beta$ expression. Among these, GRP78 was associated with the shortest progression-free survival of HCC patients treated with sorafenib. Conclusion: GRP78 can be a predictive biomarker in HCC patients treated with sorafenib. Strategies designed to inhibit the GRP78-related pathway may overcome sorafenib resistance.

Hepatocellular carcinoma (HCC) contributed to almost $80 \%$ of all liver cancers and was the second leading cause of cancer-related deaths in Taiwan in 2014 (1). More than half of HCC cases are diagnosed late and patients with advanced HCC have a median survival of less than one year (2). Patients with vascular invasion or extrahepatic spread are categorized as having advanced disease and are not suitable candidates for radical therapies. Systemic chemotherapy has not been proven to be consistently efficacious in treating hepatocellular carcinoma (3). Sorefanib, a dual-action Raf kinase and vascular endothelial growth factor (VEGF) inhibitor, prevents tumor growth by two anticancer activities: inhibition of tumor cell proliferation and tumor angiogenesis. This drug has been demonstrated to be well tolerated and clinical benefits have been observed in advanced refractory solid tumors (4). It has been associated with a $37 \%$ increase in overall survival (equivalent to a gain of nearly 3 months) as compared with placebo in patients with advanced hepatocellular carcinoma and compensated cirrhosis (5).

The response of sorafenib in HCC treatment is relatively inconsistent and acquired resistance is an emerging issue nowadays. To investigate the acquired resistance to sorafenib, several mechanisms have been proposed such as crossinteraction between PI3K/Akt and JAK-STAT pathways, the 
activation of hypoxia-induced factor and epithelialmesenchymal transition and so on (6). Two-dimensional gel electrophoresis (2DE) is a proteomic approach used to detect differences in protein expression in cells. Previous studies have developed a sorafenib-resistant HCC cell line from Huh7, a human HCC cell line, by long-term exposure of cells to sorafenib treatment (7). Herein, we analyzed the differences in protein expression between the parental cells and sorafenib resistant cells by using 2DE assay. Therefore, potential targets related to sorafenib resistance could be evaluated in human subjects.

\section{Materials and Methods}

Cell lines and reagents. The human HCC cell line Huh7 was cultured in Dulbecco's modified Eagle's medium (DMEM) supplemented with $10 \%$ fetal bovine serum. The sorafenib-resistant Huh7 cell line (Huh7-R) which was routinely maintained under constant culture conditions containing sorafenib was established in the laboratory of Dr. Kuen-Feng Chen (7). Sorafenib tosylate was kindly provided by Bayer (Leverkusen, Germany). Anti-GRP78 antibody (C50B12) was purchased from Cell Signaling Technology (Danvers, MA, USA), anti-14-3-3e antibody (SC-2395) from Santa Cruz Biotechnology (Santa Cruz, CA, USA), and anti-heat shock protein $90 \beta$ (HSP90 $\beta$ ) (ab53497) from Abcam (Cambridge, UK).

Isoelectric focusing and SDS-polyacrylamide gel electrophoresis (SDS-PAGE). We performed $2 \mathrm{DE}$ as described before with some modifications (8). The $18 \mathrm{~cm}$ immobibline dry strips (GE Healthcare Bio-Sciences AB, Uppsala, Sweden) with a $\mathrm{pH}$ range between $4 \sim 7$ were rehydrated for $16 \mathrm{~h}$ at $20^{\circ} \mathrm{C}$ with $300 \mu \mathrm{l}$ rehydration buffer and loaded with $100 \mu \mathrm{g}$ protein lysates prepared from Huh7 or Huh7-R cells using BioRad Protean IEF Cell. The proteins were isoelectrically focused at $20^{\circ} \mathrm{C} 50 \mathrm{~V}, 100 \mathrm{~V}, 200 \mathrm{~V}$, $500 \mathrm{~V}, 1,000 \mathrm{~V}, 5,000 \mathrm{~V}$, and $8,000 \mathrm{~V}$. The total voltage-hours were 81434 . The equilibrated gel was loaded onto the top of a $12.5 \% \mathrm{w} / \mathrm{v}$ polyacrylamide gel. Then, using the Biorad Protein IIxi, proteins were separated at $420 \mathrm{~V}$ after equilibrated in equilibration buffer containing $2 \% \mathrm{w} / \mathrm{v}$ DTT and $5 \% \mathrm{w} / \mathrm{v}$ iodoacetamide.

Image analysis and statistical analysis. 2DE gels were stained with LavaPurple $^{\mathrm{TM}}$ followed by the image capture of 2DE gel map. Then the image scan was obtained by using Typhoon 9400 fluorescence scanner (GE healthcare) with green laser (green laser PMT: 600 volt and emission filter: $580 \mathrm{BP}$ ). A total of 7 pairs of well-focused gel maps collected from control Huh7 cells and Huh7-R cells were compared by PDQuest 8.0.1 (BioRad) software to define the differentially expressed proteins in Huh7-R cells. The results were visually confirmed. The intensity of the spot was measured and normalized as a percentage of the total intensities of all spots in a gel (total normalized volume). These individual protein spots with normalized volumes across replica gels of $0.5 \%(\mathrm{v} / \mathrm{v})$ DMSO- or Huh7-R cells were first determined by the normal distribution test and Student's t-Test (STATISTICA, StatSoft, Tulsa, OK, USA) for each differentially expressed protein spot. Log transformation was performed followed by the normal distribution test and Student's $t$ Test if normal distribution was not acquired. To evaluate the statistical variance of sorafenib resistance, the differences were considered statistically significant at $p<0.05$ by Student's $t$-Test. Furthermore, the differentially expressed proteins present at least in 4 out of 7 gel pairs were considered as sorafenib resistance-impacted proteins.

In-gel digestion and protein identification analysis via liquid chromatography-tandem mass spectrometry (LC-MS). The protein spots of interest were selected for in-gel digestion using silver staining. Silver staining, in-gel digestion and mass spectrometric protein identification, were performed as described previously $(8,9)$. Briefly, we separated the protein digest in LTQ-Orbitrap hybrid tandem mass spectrometer system (ThermoFisher, San Jose, CA, USA). Agilent 1200 nanoflow HPLC system was equipped with LC Packing C18 PepMap 100 (length: $5 \mathrm{~mm}$; internal diameter: $300 \mu \mathrm{m}$; bead size: $5 \mu \mathrm{m}$ ) as the trap column. The separating column was Agilent ZORBAX XDB-C18 (length: $50 \mathrm{~mm}$; internal diameter: 75 $\mu \mathrm{m}$; bead size: $3.5 \mu \mathrm{m}$ ). Extraction of the MS/MS information as well as calculation of the charge and mass for each analyzed peptide were obtained by using File Converter in Xcalibur 2.0SR package (ThermoFisher) and an in-house program. To search the best matched peptides from a non-redundant protein database, TurboSequest program (ver.27, rev.11) was applied using the FASTA sequences downloaded from National Center for Biotechnology Information (http://www.ncku.nim.nih.gov/guide/proteins/\#tab-all) on 2010/10/12 with 541927 entries. The mass ranges during the database search were 1 and $3.5 \mathrm{~m} / \mathrm{z}$ for fragment and precursor ions, respectively, when the tryptic peptides with $\leq 2$ missed cuts were considered. The protein identities were documented only when at least two peptides have matched the conditions listed below: high Xcore (i.e., $\geq 2.0$ for doubly charged peptides and $\geq 3.0$ for triply charged ones) and minimal differences between observed and hypothetical masses (i.e., $\Delta \mathrm{M}<10 \mathrm{ppm}$ ). In order to verify the effectiveness of the entire protein identification procedure including in-gel digestion, nanoflow HPLC, MS/MS and informatics analysis, $26 \mathrm{fmol}$ of BSA in gel was obtained for each set of MS/MS analysis. Only when $10 \mathrm{ppm}$ mass accuracy and over $70 \%$ coverage was detected for the co-processed BSA sample, the experimental data were confirmed.

Tumor samples. Sixty patients were included retrospectively, who were treated with sorafenib and had a pathological diagnosis of hepatocellular carcinoma between 2006 and 2014 in Chi Mei Medical Center. Pathological, demographic and survival data of these patients were retrieved from medical records. All tumors were harvested from primary liver sites. All tumors were histologically characterized and graded according to Edmondson's scales and grouped as well differentiated, moderate and poorly differentiated. The study was approved by the institutional Review Board of the Chi Mei Medical Center (No. 10212-001).

Immunohistochemical staining. Staining was carried out on formalin-fixed and paraffin-embedded tissue sections using a twostep protocol (Novolink Polymer Detection System, Novocastra) according to the manufacturer's instructions. Briefly, paraffin sections were deparaffinized first and then hydrated. After microwave antigen retrieval, as required, slides were washed for 5 min in phosphate buffered saline (PBS). We used peroxidase block for $5 \mathrm{~min}$ to neutralize endogenous peroxidase. Following incubation, the sections were washed in PBS $(2 \times 5$ min washes $)$. Sections were incubated with protein block for $5 \mathrm{~min}$ and washed again in PBS $(2 \times 5 \mathrm{~min}$ washes $)$. Primary rabbit polyclonal 


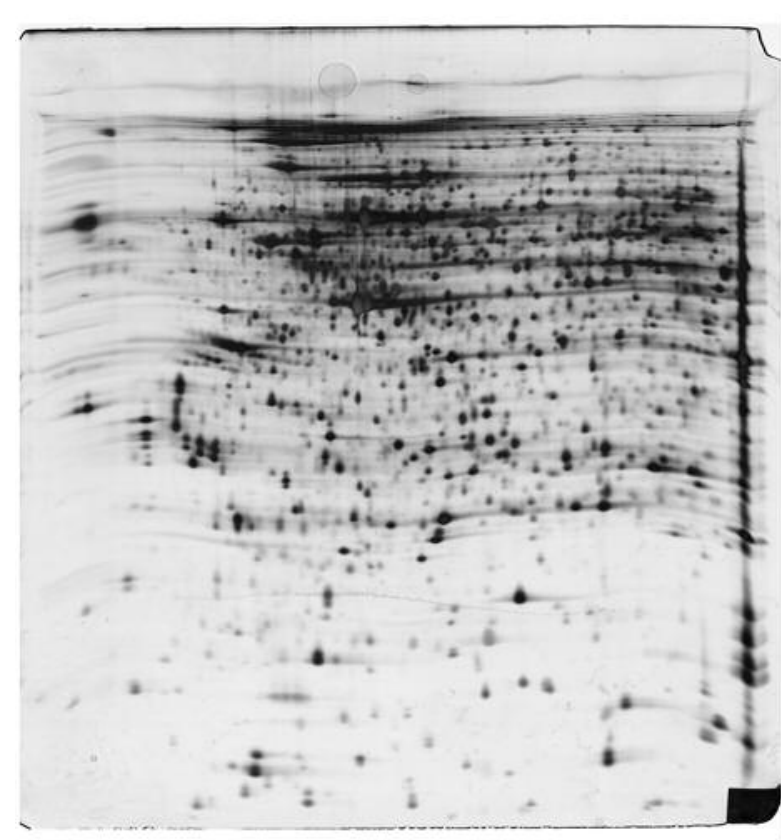

Huh7

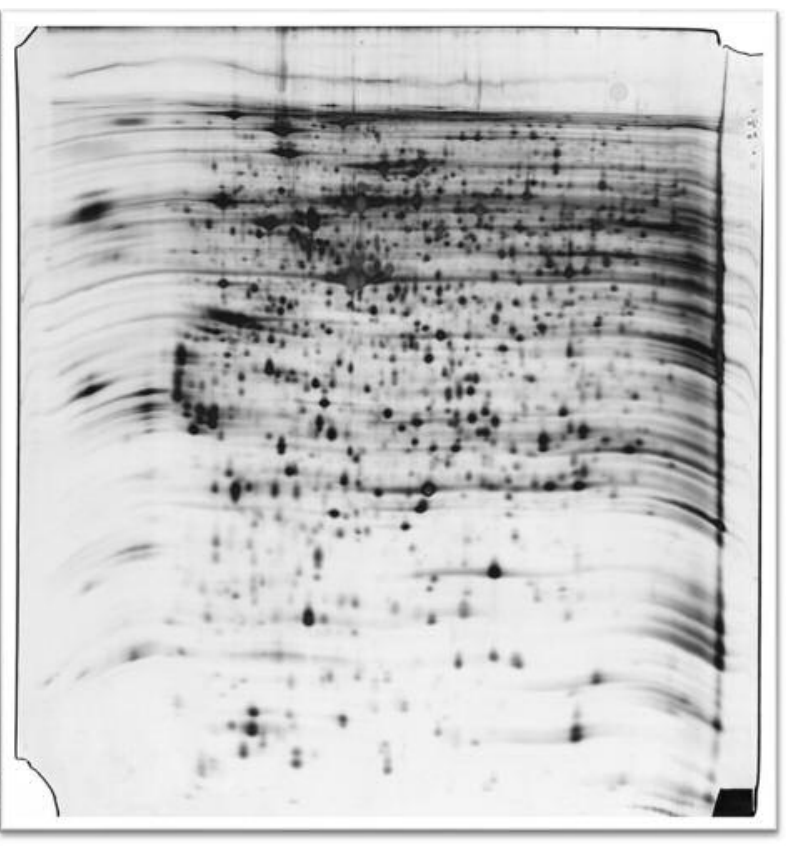

Huh7-R

Figure 1. Silver stained 2D gel electrophoresis of parental Huh7 cells and Huh7-R cell lysates. Protein lysates were prepared from Huh7 cells (left) and Huh7-R cells (right), as described in Materials and Methods.

antibodies used were anti-human-14-3-3ع (3570, Cell Signaling Technology), HSP90ßab (MA5-14057, Thermo Fisher Scientific, Cheshire, UK) and GRP78 (ab12158, Abcam, Cambridge, UK). After serial incubation with primary antibodies overnight at $4{ }^{\circ} \mathrm{C}$, the sections were washed in PBS $(2 \times 5$ min washes $)$ and incubated with post-primary for $10 \mathrm{~min}$. In the next steps, slides were washed in PBS $(2 \times 5$ min washes), incubated with Novolink polymer for 10 min and then washed in PBS ( $2 \times 5$ min with gentle rocking on an orbital shaker). 3-3-diaminobenzidine working solution was applied to the slides for $3 \mathrm{~min}$. Slides were washed in PBS, counterstained with hematoxylin for $1 \mathrm{~min}$ and washed in di- $\mathrm{H}_{2} \mathrm{O}$ for $5 \mathrm{~min}$ before dehydration, clearing and mounting. To evaluate the expression of indicated proteins, slide scorings were based on intensity of stain (0-3). The intensities of expression 0 and 1 were categorized as low expression. On the other hand, 2 and 3 were defined as high expression.

Immunoblotting. Immunoblotting analysis was performed according to a standard method. The primary antibodies used for immunoblotting analysis included anti-human-14-3-3e (3570, Cell Signaling Technology), HSP90ßab (MA5-14057, Thermo Fisher Scientific, Cheshire, UK), GRP78 (ab12158, Abcam) and $\beta$-actin (SigmaAldrich). Following incubation with the secondary antibodies for $2 \mathrm{~h}$, protein-antibody complexes were detected using the ECL system (Millipore) and visualized with a Biospectrum AC imaging system (UVP, Cambridge, UK).

Statistical analysis. Survival was statistically analyzed by the Kaplan-Meier survival curve and a log-rank test performed with SigmaPlot 12.0 software (Systat Software Inc., San Jose, CA, USA).

\section{Results}

Two-dimensional gel electrophoresis of Huh7-R cells and parental Huh7 cells. Previously, we have established Huh7R HCC cells by long-term exposure to sorafenib at low doses escalating to higher doses for a long period of time. Furthermore, parental Huh7 cells showed apoptosis in the presence of sorafenib in a dose-dependent manner. In contrast, Huh7-R cells revealed resistance to sorafenibinduced apoptosis, even at $10 \mu \mathrm{M}$ (the highest clinical achievable concentration) (7). To analyze the mechanism of acquired resistance to sorafenib, the protein expression profile of parental Huh7 and Huh7-R cell lines was analysed by 2DE coupled LC-MS/MS. To prevent the gel-gel variation, seven replicate gel pairs were collected from different protein harvests. The representative 2D maps of parental Huh7 cells and Huh7-R cells are depicted in Figure 1.

Identification of differential expressed proteins between parental Huh7 cells and Huh7-R cells. After the proteomic comparison, over-expressed proteins and under-expressed proteins were identified. Among these, 13 proteins were differentially expressed with a magnitude near or higher than two-fold between Huh7 and Huh7-R cells, in at least 4/7 gel pairs. The protein spots of interest were picked up for in-gel digestion using silver staining. The protein spots 
Table I. Differentially expressed proteins identified by tandem mass spectrometry.

\begin{tabular}{|c|c|c|c|c|c|c|c|}
\hline Protein identity & Incidence & $\begin{array}{l}\text { Experiment } \\
\text { PI/MW } \\
(\mathrm{kDa})\end{array}$ & $\begin{array}{l}\text { Theoretical } \\
\text { PI/MW } \\
(\mathrm{kDa})\end{array}$ & $\begin{array}{l}\text { Matched } \\
\text { peptide } \\
\text { number }\end{array}$ & $\begin{array}{l}\text { Coverage } \\
(\%)^{\mathrm{b}}\end{array}$ & $\begin{array}{l}\text { Accession } \\
\text { number } \\
(\mathrm{NCBI})\end{array}$ & Fold \\
\hline $78 \mathrm{kDa}$ glucose-regulated protein & $4 / 7$ & $5.0 / 88.1$ & $5.01 / 82.6$ & 29 & 62.1 & 14916999 & 6.8 \\
\hline ATP synthase subunit beta, mitochondrial & $6 / 7$ & $5.7 / 57$ & $5.26 / 56.6$ & 8 & 28.7 & 114549 & -2.9 \\
\hline $\begin{array}{l}\text { Delta( } 3,5) \text {-Delta }(2,4) \text {-dienoyl-CoA isomerase, } \\
\text { mitochondrial precursor }\end{array}$ & $5 / 7$ & $6.6 / 34.3$ & $8.16 / 35.8$ & 4 & 27.1 & 70995211 & 4.3 \\
\hline 14-3-3 protein epsilon & $5 / 7$ & $4.5 / 32.7$ & $4.63 / 29.2$ & 11 & 62.7 & 51702210 & 2.4 \\
\hline Annexin A3 & $7 / 7$ & $6.1 / 35.3$ & $5.58 / 36.4$ & 10 & 44.6 & 113954 & 4.1 \\
\hline Triosephosphate isomerase 1 , isoform CRA-b & $4 / 7$ & $6.6 / 29.4$ & $5.65 / 30.8$ & 9 & 41.3 & 119609128 & -2.5 \\
\hline NADH-ubiquinone oxidoreductase $23 \mathrm{kDa}$ subunit & $5 / 7$ & $5.4 / 27.4$ & $6 / 23.71$ & 4 & 28.6 & 2499325 & 4.8 \\
\hline COMM domain-containing protein 10 & $4 / 7$ & $6.6 / 26.8$ & $6.09 / 22.97$ & 6 & 43.1 & 51316122 & -2.2 \\
\hline Heat shock protein HSP 90-beta & $4 / 7$ & $4.8 / 95.4$ & $5.07 / 98.2$ & 26 & 54.6 & 17865718 & 4.2 \\
\hline Actin-like 6A, isoform CRA-c & $4 / 7$ & $5.9 / 52.3$ & $5.39 / 47.5$ & 12 & 36.8 & 119598807 & 2.6 \\
\hline Capping protein (actin filament), gelsolin-like, isoform CRA-a & $4 / 7$ & $6.4 / 41.2$ & $5.83 / 41.8$ & 6 & 36.5 & 119619923 & 2.5 \\
\hline $\begin{array}{l}\text { Chain A, Crystal Structure Of A Complex Between } \\
\text { Protein Phosphatase } 1 \text { Alpha (pp1), The Pp1 Binding } \\
\text { And Pdz Domains Of Spinophilin And The Small Natural } \\
\text { Molecular Toxin Nodularin-r }\end{array}$ & $4 / 7$ & $6.3 / 39.2$ & $6.21 / 37.3$ & 6 & 24.6 & 291463445 & -2.8 \\
\hline Chromosome 12 open reading frame 10 , isoform CRA-b & $4 / 7$ & $6.2 / 41.1$ & $6.35 / 42.5$ & 6 & 19.7 & 119617094 & -2.4 \\
\hline
\end{tabular}

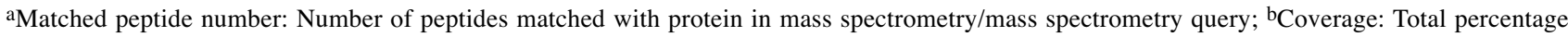
of amino acid sequence covered by peptides identified by mass spectrometry/mass spectrometry query.

of interest were identified by mass spectrometric protein identification and the results are listed in Table I. Among these deregulated proteins, three proteins were targeted based on their high-fold alterations, including GRP78, 14-3-3 $\varepsilon$ protein, and HSP90 $\beta$.

Immunohistochemical staining of indicated proteins in $\mathrm{HCC}$ tissues. Tumor samples from sixty advanced HCC patients treated with sorafenib were collected for immunohisto-chemical analysis of GRP78, 14-3-3e, and HSP90 $\beta$. The clinical characteristics of patients are listed in Table II. First, expression of HSP90 $\beta$, GRP78 and 14-3-3e in parental Huh7 and Huh7-R cells was examined by immunoblotting. Stronger expression of HSP90 $\beta$, GRP78 and 14-3-3e were detected in Huh7-R cells compared with parental Huh7 cells (Figure 2A). Second, expression of HSP90 $\beta$, GRP78 and 14-3-3ع in patient samples was examined by immunocyto-chemistry. The expression of indicated proteins was categorized as high expression or low expression based on intensity (Figure 2B). $73 \%$ of tumor samples had high expression of GRP78, 18\% had high 14-3-3e expression and $85 \%$ high HSP90 $\beta$ expression.

High expression of GRP78 correlated with shorter progression free survival in HCC patients treated with sorafenib. Patients with high expression of GRP78 HCC had shorter progression free survival (PFS) following sorafenib treatment. The median PFS in the high GRP78 expression group was 2.20 months (95\% confidence interval $=2.42-5.10)$ significantly shorter
Table II. Demographics of HCC patients treated with sorafenib.

\begin{tabular}{lccc}
\hline & $\mathrm{n}(\%)$ & $\mathrm{n}(\%)$ & $\mathrm{n}(\%)$ \\
\hline Age $(<60: \geq 60)$ & $26(43)$ & $34(57)$ & \\
Gender (M:F) & $49(82)$ & $11(18)$ & \\
BCLC (A:B:C) & $3(5)$ & $15(25)$ & $42(70)$ \\
Diabetes (Y:N) & $17(28)$ & $43(72)$ & \\
Hepatitis B (Y:N) & $35(58)$ & $25(42)$ & \\
Hepatitis C (Y:N) & $20(33)$ & $40(67)$ & \\
GRP78 expression (L:H) & $16(27)$ & $44(53)$ & \\
14-3-3E expression (L:H) & $49(82)$ & $11(18)$ & \\
HSP90 $\beta$ expression (L:H) & $9(15)$ & $51(85)$ & \\
\hline
\end{tabular}

aBCLC: Barcelona Clinic Liver Cancer staging system.

compared with 4.73 months ( $95 \% \mathrm{CI}=4.45-14.27)$ in the low GRP78 expression group $(p=0.008)$. Furthermore, low expression of $14-3-3 \varepsilon$ tended to associate with poor progression-free survival, but it did not reach statistical significance. Regarding HSP90 $\beta$, the expression intensity did not correlate with survival (Figure 3).

\section{Discussion}

Sorafenib had been demonstrated to involve several targets in inhibiting cancer cell growth: Serine-threonine kinase Raf-1 and B-Raf in RAF/MEK/ERK pathway, RET, FLT-3, the receptor tyrosine kinase activity of vascular endothelial 
A

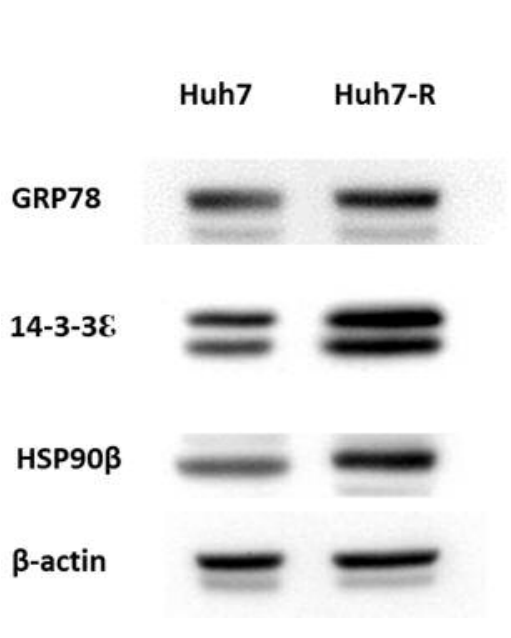

B

GRP78

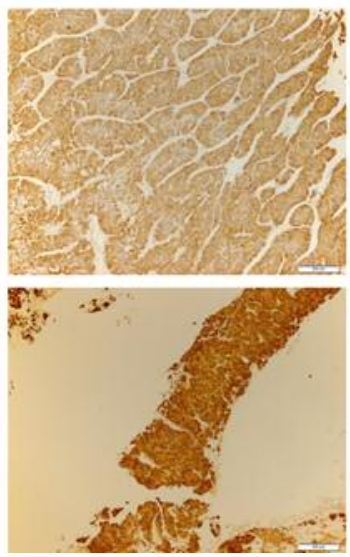

14-3-38

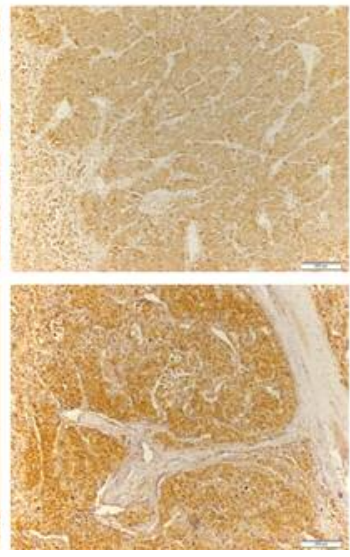

HSP90ß

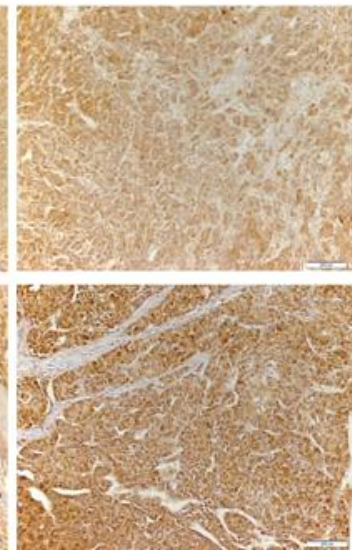

Figure 2. A. Immunoblotting of the expression of GRP78, 14-3-3E and HSP90 $\beta$ in parental Huh7 and Huh7-R cells. B. Immunohistochemistry stainins of GRP78, 14-3-3E and HSP90 $\beta$ in human HCC tumors. The indicated protein expression was categorized as low or high.

A

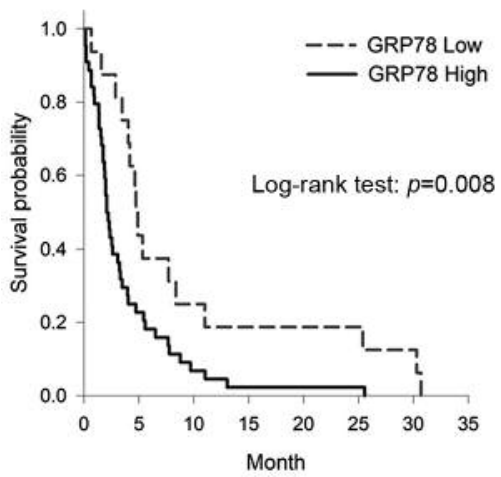

B

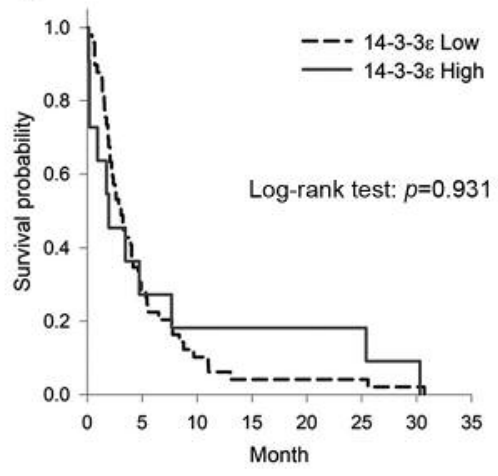

C

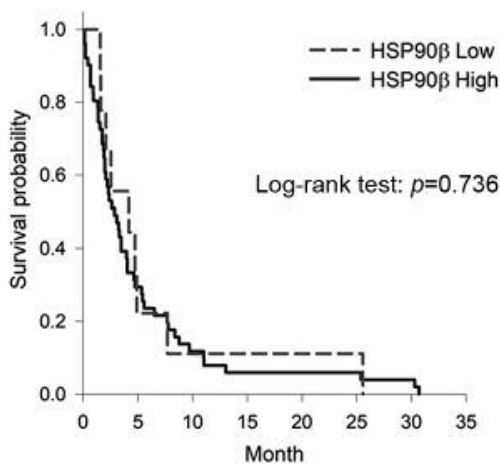

Figure 3. Progression-free survival categorized by the expressions of indicated proteins. A: GRP78, B: 14-3-3E, C: HSP90.

growth factor receptors (VEGFRs) $1,2,3$ and plateletderived growth factor receptor- $\beta$ (PDGFR- $\beta)(10)$. The clinical efficacy of sorafenb in treating patients with ChildPugh A stage C HCC has been documented by two phase III randomized, placebo-controlled trials: the SHARP study and the Asia-Pacific study (ORIENTAL) in terms of benefit on overall survival, time to radiologic progression and disease control rate $(5,11)$. Sorafenib seems to be effective to prolong the median survival time with limited side effects in patients with advanced HCC, but the primary resistance and acquired resistance to sorafenib has become an obstacle to extend the clinical efficacy of sorafenib.
More than half of HCC patients have epidermal growth factor receptor (EGFR) over-expression and abnormal activation. Abnormal activation of EGFR/human epidermal receptor type 3 (HER3) as well as overexpression of both EGFR and its ligand can inhibit the effect of sorafenib on suppressing tumor growth. Overexpression of EGFR or its ligand in HCC cells may relate to primary resistance of sorafenib (12). In addition to EGFR and its ligand, downstream signaling molecules also contributed to sorafenib resistance. Down-regulation of $\mathrm{pERK}$ and expression of c-Jun $\mathrm{N}$-terminal kinase can predict the sensitivity to sorafenib $(13,14)$. 
In regards to the acquire resistance to sorafenib, many mechanisms have been extensively studied, including PI3K/Akt pathway, autophagy, epithelial-mesenchymal transition, tumor microenvironment, and epigenetic regulation. An emerging theory focuses on the angiogenic strategy to acquire resistance to cancer treatment, including sorafenib. It proposes vessel co-option, where the tumor hijacks the existing vasculature in organs such as the lung and liver, limiting the tumor's need for angiogenesis. An orthotopic human HCC model revealed that up to $75 \%$ of total vessels were provided by vessel co-option in resistant tumors relative to $23 \%$ in untreated control (15).

GRP78 is a molecular chaperone involved in endoplasmic reticulum stress response and can be regulated by the transcription factors ATF6 and XBP1 which play important role in regulation of tumor proliferation, invasion and metastasis $(16,17)$. GRP78 was up-regulated in HCC tumors and correlated with Granulin-epithelin precursor expression (18). The development of acquired resistance to systemic treatment limits the extension of survival of patients with advanced HCC. Treatment human leukemia cells (U937) with sorafenib can induce endoplasmic reticulum stress by immediate cytosolic calcium mobilization, GADD34 protein induction, PKR-like ER kinase and eukaryotic initiation factor $2 \alpha$ phosphorylation, XBP1 splicing, and a general reduction in protein synthesis as assessed by $\left[{ }^{35} \mathrm{~S}\right]$ methionine incorporation. It was accompanied with pronounced generation of reactive oxygen species through a mechanism dependent on cytosolic calcium mobilization and a significant decline in GRP78/Bip protein levels (19). In agreement, the expression of GRP78 has been associated with a wide range of therapies, including chemotoxic, antihormonal, DNA damaging and anti-angiogenesis agents in several cancers (20). The contribution of GRP78 in acquired resistance to sorafenib has been studied in HCC cells. Another study used HepJ5 (a GRP78-overexpressing HCC cells) and HepG2 cells as a paired matched control to determine the acquired resistance to sorafenib in HCC cells (21). Further studies suggested that GRP78 can be detected in serum samples of HCC patients. Also, secreted GRP78 facilitated proliferation and inhibited apoptosis induced by sorafenib both in HCC cell lines and xenografts. GRP78 can interact with EGFR, activate EGFR-SRC-STAT3 pathway, conferring the resistance of sorafenib (22). Questiomycin, a suppressor of GRP78 by promoting its degradation, enhanced the anti-tumor effect of sorafenib in HCC xenograft models (23). Importantly, high expression of GRP78 was associated with inferior survival of HCC patients in our study. It substantially supported the role of GRP78 in acquired resistance to sorafenib therapy of HCC.

14-3-3 proteins comprise seven isoforms and share highly conserved homology among all eukaryotic cells. The biological functions of 14-3-3 proteins influence cell development, cell cycle regulation, DNA repair, cell proliferation, apoptosis, adhesion, motility, and tissue response to injury (24). Several studies have demonstrated that $14-3-3 \beta, 14-3-3 \varepsilon, 14-3-3 \gamma, 14-3-3 \sigma$ and $14-3-3 \xi$ isoforms are overexpressed in HCC and expression of 14-3$3 \varepsilon$ is associated with inferior overall and progression free survival (25). Among these 14-3-3 proteins, $14-3-3 \zeta$ is conjugated with $\alpha \mathrm{B}$-Crystallin to promote $\mathrm{HCC}$ progression and has been demonstrated to be involved in sorafenib resistance in vitro and patients with HCC (26). In our study, 14-3-3e was overexpressed in Huh7-R cells but it failed to contribute to sorafenib resistance in patients with HCC. The effect of $14-3-3 \varepsilon$ on sorafenib resistance remains uncertain based on our analysis and previous studies (25). HSP is normally maintained at low levels but it is induced under protein-damage conditions. HSP70, not HSP90, is downstream of heat shock fctor- $1 \alpha$ which is activated by $14-$ $3-3 \sigma$ and $\beta$-catenin. The biological functions of HSP70 include enhancement of cell migration and endothelialmesenchymal transition $(27,28)$. Up to date, only clusterin, an ATP-independent molecular chaperone with HSPs-like properties, has been reported to confer resistance to sorafenib from an unpublished data (28).

The overall treatment for advanced HCC remains unsatisfied and novel agents targeting sorafenib resistance or other pathways are strongly desired. Recently clinical trials have indicated that selective c-Met inhibitors have anti-tumor activity in HCC with acceptable safety and tolerability in patients with Pugh A liver reserve. It is required to continue the exploration of the clinical benefit of c-Met inhibition in HCC treatment. Before this achievement, it is mandatory to conquer sorafenib resistance by targeting GRP78 and further research focused on this strategy should be encouraged.

\section{Conclusion}

In conclusion, we enforced the evidence that GRP78 contributes to the resistance to sorafenib in HCC by in vivo and clinical analysis. The results are consistent with other preliminary studies and present a primary target for overcoming sorafenib resistance.

\section{Conflicts of Interest}

All Authors have no potential conflicts of interest to declare regarding this study.

\section{Authors' Contributions}

YHF, CJT and TFW wrote the manuscript. YHF and CLT conducted the process of experiments. YHF, YCS, CJT and TFW designed the study and data interpretation. YHF, YCS and CLT prepared the organization of figures and statistical analysis. All Authors verified the content of the manuscript. 


\section{Acknowledgements}

The Authors appreciate the generous donation of the cell lines, Huh7-R from Dr. Kuen-Feng Chen (National Taiwan University).

\section{References}

1 Leung HWC and Chan ALF: Cost-utility of stereotactic radiation therapy versus proton beam therapy for inoperable advanced hepatocellular carcinoma. Oncotarget 8(43): 75568-75576, 2017. PMID: 29088891. DOI: 10.18632/oncotarget.17369

2 Llovet JM, Burroughs A and Bruix J: Hepatocellular carcinoma. Lancet 362(9399): 1907-1917, 2003. PMID: 14667750. DOI: 10.1016/S0140-6736(03)14964-1

3 El-Serag HB: Hepatocellular carcinoma. N Engl J Med 365(12): 1118-1127, 2011. PMID: 21992124. DOI: 10.1056/NEJMra 1001683

4 Strumberg D, Richly H, Hilger RA, Schleucher N, Korfee S, Tewes M, Faghih M, Brendel E, Voliotis D, Haase CG, Schwartz B, Awada A, Voigtmann R, Scheulen ME and Seeber S: Phase I clinical and pharmacokinetic study of the novel raf kinase and vascular endothelial growth factor receptor inhibitor bay 439006 in patients with advanced refractory solid tumors. J Clin Oncol 23(5): 965-972, 2005. PMID: 15613696. DOI: 10.1200/ JCO.2005.06.124

5 Llovet JM, Ricci S, Mazzaferro V, Hilgard P, Gane E, Blanc JF, de Oliveira AC, Santoro A, Raoul JL, Forner A, Schwartz M, Porta C, Zeuzem S, Bolondi L, Greten TF, Galle PR, Seitz JF, Borbath I, Haussinger D, Giannaris T, Shan M, Moscovici M, Voliotis D and Bruix J: Sorafenib in advanced hepatocellular carcinoma. N Engl J Med 359(4): 378-390, 2008. PMID: 18650514. DOI: $10.1056 /$ NEJMoa0708857

6 Zhu YJ, Zheng B, Wang HY and Chen L: New knowledge of the mechanisms of sorafenib resistance in liver cancer. Acta Pharmacol Sin 38(5): 614-622, 2017. PMID: 28344323. DOI: 10.1038/aps.2017.5

7 Chen KF, Chen HL, Tai WT, Feng WC, Hsu CH, Chen PJ and Cheng AL: Activation of phosphatidylinositol 3-kinase/akt signaling pathway mediates acquired resistance to sorafenib in hepatocellular carcinoma cells. J Pharmacol Exp Ther 337(1): 155-161, 2011. PMID: 21205925. DOI: 10.1124/jpet.110.175786

8 Wu TF, Hsu LT, Tsang BX, Huang LC, Shih WY and Chen LY: Clarification of the molecular pathway of taiwan local pomegranate fruit juice underlying the inhibition of urinary bladder urothelial carcinoma cell by proteomics strategy. BMC Complement Altern Med 16: 96, 2016. PMID: 26955879. DOI: 10.1186/s12906-016-1071-7

9 Liao KA, Tsay YG, Huang LC, Huang HY, Li CF and Wu TF: Search for the tumor-associated proteins of oral squamous cell carcinoma collected in taiwan using proteomics strategy. J Proteome Res 10(5): 2347-2358, 2011. PMID: 21322651. DOI: $10.1021 / \mathrm{pr} 101146 \mathrm{w}$

10 Le Grazie M, Biagini MR, Tarocchi M, Polvani S and Galli A: Chemotherapy for hepatocellular carcinoma: The present and the future. World J Hepatol 9(21): 907-920, 2017. PMID: 28824742. DOI: $10.4254 /$ wjh.v9.i21.907

11 Cheng AL, Kang YK, Chen Z, Tsao CJ, Qin S, Kim JS, Luo R, Feng J, Ye S, Yang TS, Xu J, Sun Y, Liang H, Liu J, Wang J, Tak WY, Pan H, Burock K, Zou J, Voliotis D and Guan Z: Efficacy and safety of sorafenib in patients in the asia-pacific region with advanced hepatocellular carcinoma: A phase III randomised, double-blind, placebo-controlled trial. Lancet Oncol 10(1): 25-34, 2009. PMID: 19095497. DOI: 10.1016/S14702045(08)70285-7

12 Ezzoukhry Z, Louandre C, Trecherel E, Godin C, Chauffert B, Dupont S, Diouf M, Barbare JC, Maziere JC and Galmiche A: EGFR activation is a potential determinant of primary resistance of hepatocellular carcinoma cells to sorafenib. Int J Cancer 131(12): 2961-2969, 2012. PMID: 22514082. DOI: 10.1002/ ijc. 27604

13 Zhang Z, Zhou X, Shen H, Wang D and Wang Y: Phosphorylated ERK is a potential predictor of sensitivity to sorafenib when treating hepatocellular carcinoma: Evidence from an in vitro study. BMC Med 7(41), 2009. PMID: 19698189. DOI: 10.1186/1741-7015-7-41

14 Hagiwara S, Kudo M, Nagai T, Inoue T, Ueshima K, Nishida N, Watanabe T and Sakurai T: Activation of JNK and high expression level of CD133 predict a poor response to sorafenib in hepatocellular carcinoma. Br J Cancer 106(12): 1997-2003, 2012. PMID: 22596232. DOI: $10.1038 / b j c .2012 .145$

15 Kuczynski EA, Yin M, Bar-Zion A, Lee CR, Butz H, Man S, Daley F, Vermeulen PB, Yousef GM, Foster FS, Reynolds AR and Kerbel RS: Co-option of liver vessels and not sprouting angiogenesis drives acquired sorafenib resistance in hepatocellular carcinoma. J Natl Cancer Inst 108(8): djw030, 2016. PMID: 27059374. DOI: 10.1093/jnci/djw030

16 Shuda M, Kondoh N, Imazeki N, Tanaka K, Okada T, Mori K, Hada A, Arai M, Wakatsuki T, Matsubara O, Yamamoto N and Yamamoto M: Activation of the atf6, xbp1 and grp78 genes in human hepatocellular carcinoma: A possible involvement of the ER stress pathway in hepatocarcinogenesis. J Hepatol 38(5): 605-614, 2003. PMID: 12713871. DOI: 10.1016/S0168-8278(03)00029-1

17 Su R, Li Z, Li H, Song H, Bao C, Wei J and Cheng L: Grp78 promotes the invasion of hepatocellular carcinoma. BMC Cancer 10: 20, 2010. PMID: 20082722. DOI: 10.1186/1471-2407-10-20

18 Yip CW, Lam CY, Poon TCW, Cheung TT, Cheung PFY, Fung SW, Wang XQ, Leung ICY, Ng LWC, Lo CM, Tsao GSW and Cheung ST: Granulin-epithelin precursor interacts with 78-kda glucose-regulated protein in hepatocellular carcinoma. BMC Cancer 17(1): 409, 2017. PMID: 28601093. DOI: 10.1186/ S12885-017-3399-x

19 Rahmani M, Davis EM, Crabtree TR, Habibi JR, Nguyen TK, Dent $\mathrm{P}$ and Grant $\mathrm{S}$ : The kinase inhibitor sorafenib induces cell death through a process involving induction of endoplasmic reticulum stress. Mol Cell Biol 27(15): 5499-5513, 2007. PMID: 17548474. DOI: 10.1128/MCB.01080-06

20 Luo B and Lee AS: The critical roles of endoplasmic reticulum chaperones and unfolded protein response in tumorigenesis and anticancer therapies. Oncogene 32(7): 805-818, 2013. PMID: 22508478. DOI: $10.1038 /$ onc. 2012.130

21 Chiou JF, Tai CJ, Huang MT, Wei PL, Wang YH, An J, Wu CH, Liu TZ and Chang YJ: Glucose-regulated protein 78 is a novel contributor to acquisition of resistance to sorafenib in hepatocellular carcinoma. Ann Surg Oncol 17(2): 603-612, 2010. PMID: 19830497. DOI: 10.1245/S10434-009-0718-8

22 Li R, Yanjiao G, Wubin H, Yue W, Jianhua H, Huachuan Z, Rongjian S and Zhidong L: Secreted grp78 activates egfr-srcstat3 signaling and confers the resistance to sorafeinib in hcc cells. Oncotarget 8(12): 19354-19364, 2017. PMID: 28423613. DOI: $10.18632 /$ oncotarget 15223 
23 Machihara K, Tanaka H, Hayashi Y, Murakami I and Namba T: Questiomycin a stimulates sorafenib-induced cell death via suppression of glucose-regulated protein 78. Biochem Biophys Res Commun 492(1): 33-40, 2017. PMID: 28811106., DOI: 10.1016/j.bbrc.2017.08.042

$24 \mathrm{Wu}$ YJ, Jan YJ, Ko BS, Liang SM and Liou JY: Involvement of 14-3-3 proteins in regulating tumor progression of hepatocellular carcinoma. Cancers (Basel) 7(2): 1022-1036, 2015. PMID: 26083935. DOI: $10.3390 /$ cancers7020822

25 Ko BS, Chang TC, Hsu C, Chen YC, Shen TL, Chen SC, Wang J, Wu KK, Jan YJ and Liou JY: Overexpression of 14-3-3epsilon predicts tumour metastasis and poor survival in hepatocellular carcinoma. Histopathology 58(5): 705-711, 2011. PMID: 21401702. DOI: 10.1111/j.1365.2559.2011.03789.X

26 Huang XY, Ke AW, Shi GM, Zhang X, Zhang C, Shi YH, Wang XY, Ding ZB, Xiao YS, Yan J, Qiu SJ, Fan J and Zhou J: Alphab-crystallin complexes with 14-3-3zeta to induce epithelial-mesenchymal transition and resistance to sorafenib in hepatocellular carcinoma. Hepatology 57(6): 2235-2247, 2013. PMID: 23316005. DOI: 10.1002/hep.26255
27 Shiba-Ishii A, Kano J, Morishita Y, Sato Y, Minami Y and Noguchi M: High expression of stratifin is a universal abnormality during the course of malignant progression of earlystage lung adenocarcinoma. Int J Cancer 129(10): 2445-2453, 2011. PMID: 21207417. DOI: 10.1002/ijc.25907

28 Wang C, Zhang Y, Guo K, Wang N, Jin H, Liu Y and Qin W: Heat shock proteins in hepatocellular carcinoma: Molecular mechanism and therapeutic potential. Int J Cancer 138(8): 18241834, 2015. PMID: 26853533. DOI: 10.1002/ijc.29723
Received June 18, 2019

Revised July 24, 2019

Accepted July 25, 2019 